\title{
Improving visitor satisfaction in Egypt's Heliopolis historical district
}

\author{
Hisham Abusaada ${ }^{1}$ and Abeer Elshater ${ }^{2^{*}}$ (D)
}

\author{
* Correspondence: abeer.elshater@ \\ eng.asu.edu.eg \\ ${ }^{2}$ Department of Urban Design and \\ Planning, Ain Shams University, \\ Cairo, Egypt \\ Full list of author information is \\ available at the end of the article
}

\begin{abstract}
This study employed applied thematic analysis (ATA) and importance-performance analysis (IPA) to measure visitor satisfaction in city streets. Forty-two elements that significantly influence visitors' responses to streets and environments were included in five groups characterised by circumstances, characteristics, and indicators. Ibrahim Al-Lakani Street's atmosphere satisfaction was measured by using coherent research methods. This investigation can assist designers in developing the morphological and social composition necessary to restore a street's atmosphere and visitor satisfaction. This study contributes to the literature in two ways. First, it examines the relationships between street characteristics and visitor satisfaction in city streets regarding situations, atmospheres and social characteristics that shape these streets. Second, this study integrates ATA and IPA to create a tool for evaluating the significance, performance, and satisfaction of street situations, socio-morphological characteristics and street and visitor responses.
\end{abstract}

Keywords: Applied thematic analysis, Importance-performance analysis, Indicators, Socio-morphological characteristics, Street atmospheres

\section{Introduction}

The plausibility of the idea that the impact of an atmosphere of a city street on various types of satisfaction can be changed by changing its characteristics represents one of the dialectic topics worth reviewing in urban planning and design. These types of satisfaction include place satisfaction [23], visitor satisfaction [25], transit rider satisfaction [10], pedestrian satisfaction [15] and residents' experience and satisfaction [32]. Satisfaction is a direct expression of people's love for a place, fostering loyalty [37], and willingness to stay and deferring the intention to leave [23].

Public spaces, such as city streets, are spatial and socio-morphological spaces within urban environments where people can communicate, collaborate and maintain their social lives [26]. Each street's socio-morphological characteristics should meet human sympathy requirements and be ready to satisfy most visitors' daily life interests, at least considering completing a four-dimensional multisensory analysis: visual $[8,12]$, esthetic [7, 30], social [34] and spiritual [24, 31].

(c) The Author(s). 2021 Open Access This article is licensed under a Creative Commons Attribution 4.0 International License, which permits use, sharing, adaptation, distribution and reproduction in any medium or format, as long as you give appropriate credit to the original author(s) and the source, provide a link to the Creative Commons licence, and indicate if changes were made. The images or other third party material in this article are included in the article's Creative Commons licence, unless indicated otherwise in a credit line to the material. If material is not included in the article's Creative Commons licence and your intended use is not permitted by statutory regulation or exceeds the permitted use, you will need to obtain permission directly from the copyright holder. To view a copy of this licence, visit http://creativecommons.org/licenses/by/4.0/. The Creative Commons Public Domain Dedication waiver (http://creativecommons.org/publicdomain/zero/1.0/) applies to the data made available in this article, unless otherwise stated in a credit line to the data. 
Visitor satisfaction (VS) is associated with shopping behaviour [27], pedestrian traffic [33] and street vitality $[6,22]$. In the last decade, the topic of urban situations has been much discussed in social psychology as well as in urban planning and design. The environment of city streets arises from a variety of situations, each of which is defined by two types of urban clashes between physical and non-physical environments. These two confrontations manifest themselves through urban form, everyday life and human sensations, with street characteristics highlighting the interaction between all of these situations [2, 8]. They are also reflected in visitor response indicators (VSI), which indicate how satisfied visitors are with street spatial elements [39].

This study focuses on the changes in socio-morphological characteristics in Cairo's Heliopolis neighbourhood, which have changed gradually since the construction of a new suburb in 1905 [14, 17]. It is difficult to tell whether visitors' attitudes towards this neighbourhood's streets have improved or deteriorated since this construction. If visitors' satisfaction level has shifted, the main reasons for this shift are still unknown-and, whether they are related to human induced factors is difficult to quantify. The combined effect of multisensory experiences and urban environments has become an increasingly important part of measuring satisfaction in recent decades [1]. However, there is a gap in the existing literature regarding urban situations and atmospheres in Egyptian street environments, the relationship between socio-morphological characteristics of urban form and daily lifestyle experiences and the indicators of visitor response to street atmospheres in terms of visitor satisfaction.

This study tracked these changes through illustrated scenes from various historical eras and compared them to current scenarios to determine whether the change in characteristics affected the street atmosphere, which in turn affected the visitors' satisfaction. Subsequently, the performance of the planning and design of Ibrahim Al-Lakani Street in Heliopolis was examined. First, a systematic method for quantifying employee satisfaction was identified and two methods for addressing employee satisfaction and determining high-performance quality were selected. These two methods were 'applied thematic analysis (ATA)' [21] and 'importance-performance analysis (IPA)' $[10,25,28]$.

Thus, this study aimed to present a mixed-methods approach for assessing visitor satisfaction regarding city streets. This objective examines the street atmosphere and visitor satisfaction of Ibrahim Al-Lakani Street in Cairo's Heliopolis district as a case study that combines historical and contemporary elements, rediscovering the situation in which street characteristics and street atmosphere indicators collide. This investigation assists designers in developing the necessary morphological and social composition to restore a street's atmosphere and visitor satisfaction. This study contributes to the literature in two ways: First, it examines the relationships between street characteristics and visitor satisfaction in city streets regarding situations, atmospheres and social characteristics that shape these streets. Second, this study integrates ATA and IPA to create a tool for evaluating the significance, performance, and satisfaction of street situations, socio-morphological characteristics and visitor responses.

\section{Methods}

The case

Ibrahim Al-Lakani Street in Cairo's Heliopolis neighbourhood serves as an empirical case study (see supplementary material Appendix 3) to illustrate a developing tool. The 
reason for selecting this street was based on the cohabitation of the authors on this street for more than 25 years, which ensured ease of access to information. The collected data included information regarding people's feelings towards physical and nonphysical characteristics of the street. Figure 1 illustrates the following three diagrams concerning this case study: (i) the location of Heliopolis relative to Cairo; (ii) the components of Heliopolis district, which includes four neighbourhoods: Manshiet Bakri, ElMontaza (the Park), El-Bostan (The Orchard) and Almaza (Magazzino in Italian, which means the store); and (iii) the exact location of Ibrahim Al-Lakani Street in the ElMontaza district; Ibrahim Al-Lakani Street emerged had a different urban atmosphere, with high visitor satisfaction. Arguably, the visual image of the street changed due to morphological and socioeconomic transformations over the course of time. In the late 1940s, the neighbourhood's transformation began with the restructuring of the entrance of the district with the design of Roxy Square, alongside Roxy Cinema and a gas station, created in place of an amusement park known as Luna Park.

Ibrahim Al-Lakani Street is surrounded by numerous public service buildings as well as historical structures, including Roxy Cinema, Heliopolis Sporting Club, Horreya Mall, Cleopatra Hospital and Baron Empain Palace [16]. This cluster starts from the intersection of Al-Hejaz Street and Roxy Street and extends to the Al Ahram and Salah Salem streets. The field trip for the observation study began at Al-Hejaz Street and ended at the Cleopatra Street intersection, covering $1400 \mathrm{~m}$. The authors attempted to focus on activity patterns (to identify situations), uses and buildings on both sides of the street during this journey.

After carefully comparing the street photos to the satellite maps available on the Internet (Google Chrome and Apple Maps), the authors determined that the length of Ibrahim Al-Lakani Street to be studied should be limited to $700 \mathrm{~m}$, from Al-Hijaz Street to Al-Ahram Street, taking into consideration various obstacles to mobility and

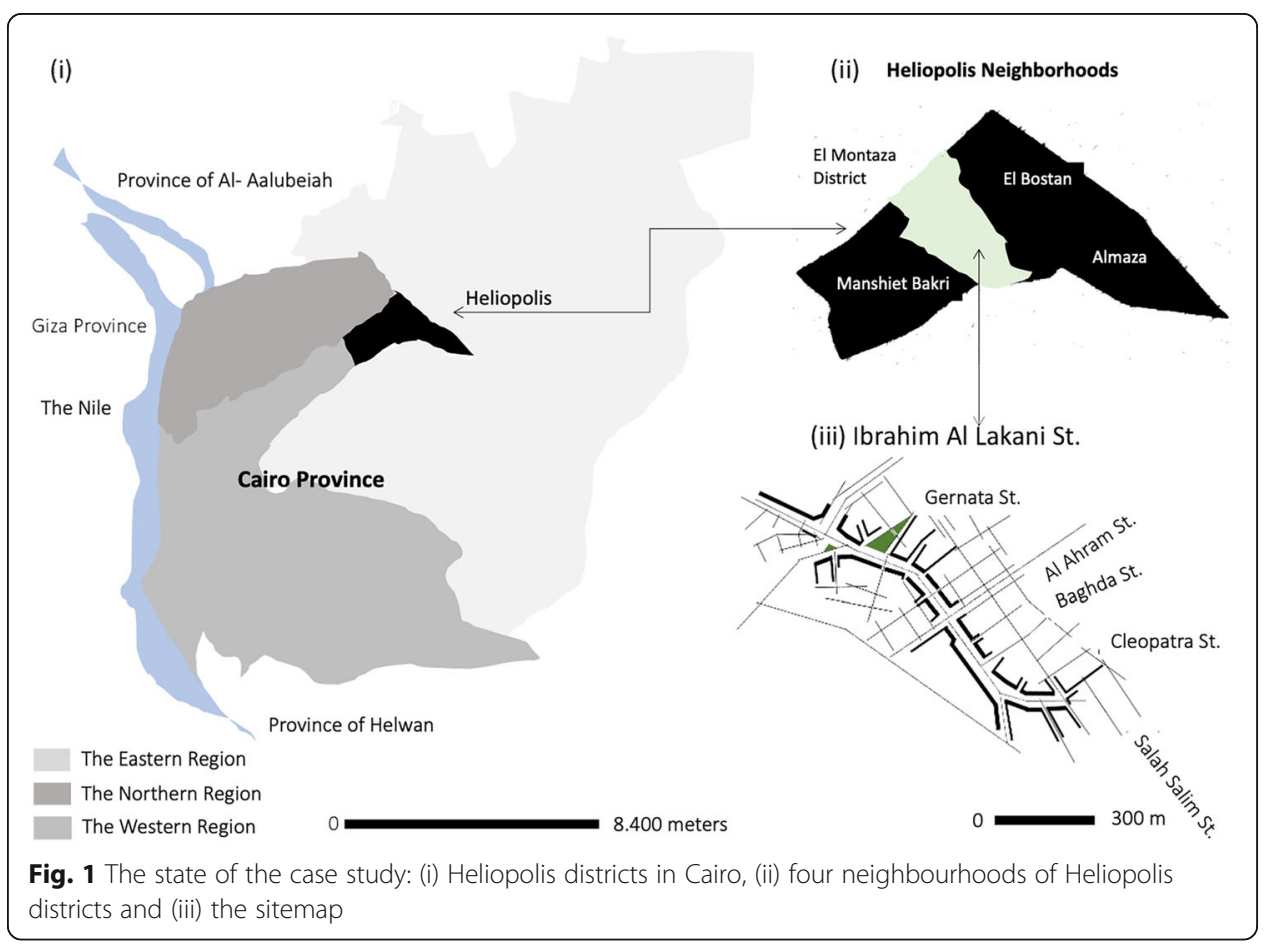


clearance for photography (Fig. 2). The selection of the study area length was made because of the impossibility of continuing the trip, as certain activities, such as the Federal Palace, restrict mobility and do not allow unrestricted photography [18]. After establishing the length of the $700 \mathrm{~m}$ route and the primary activities depicted on the base map, the authors analysed the relationships between the activities, which identified three prime areas that serve as a distinct locus for studying affective atmospheres efficiently.

\section{The theoretical framework}

The study developed a framework to measure visitor satisfaction with the street atmospheres by prioritising street characteristics and response indicators concerning this article's assumption. This framework includes three stages, data collection and analysis, statistical testing and developing a measuring tool through five steps. This article's framework is based on five concepts (Fig. 3 and Appendix 2 listed in the supplementary material Box 1).

I. Reviewing and exploring the study factors: The first stage is used applied thematic analysis (ATA) to identify the variables of the study in three groups (a) situations of the street environment (SSE) and situations of street atmospheres (SSA). (b) Social morphological characteristics (SMC). (c) Visitor response indicators (VRI) and street response indicators (SRI). This stage reviewed the study factors starting with a limited literature review (step 1),

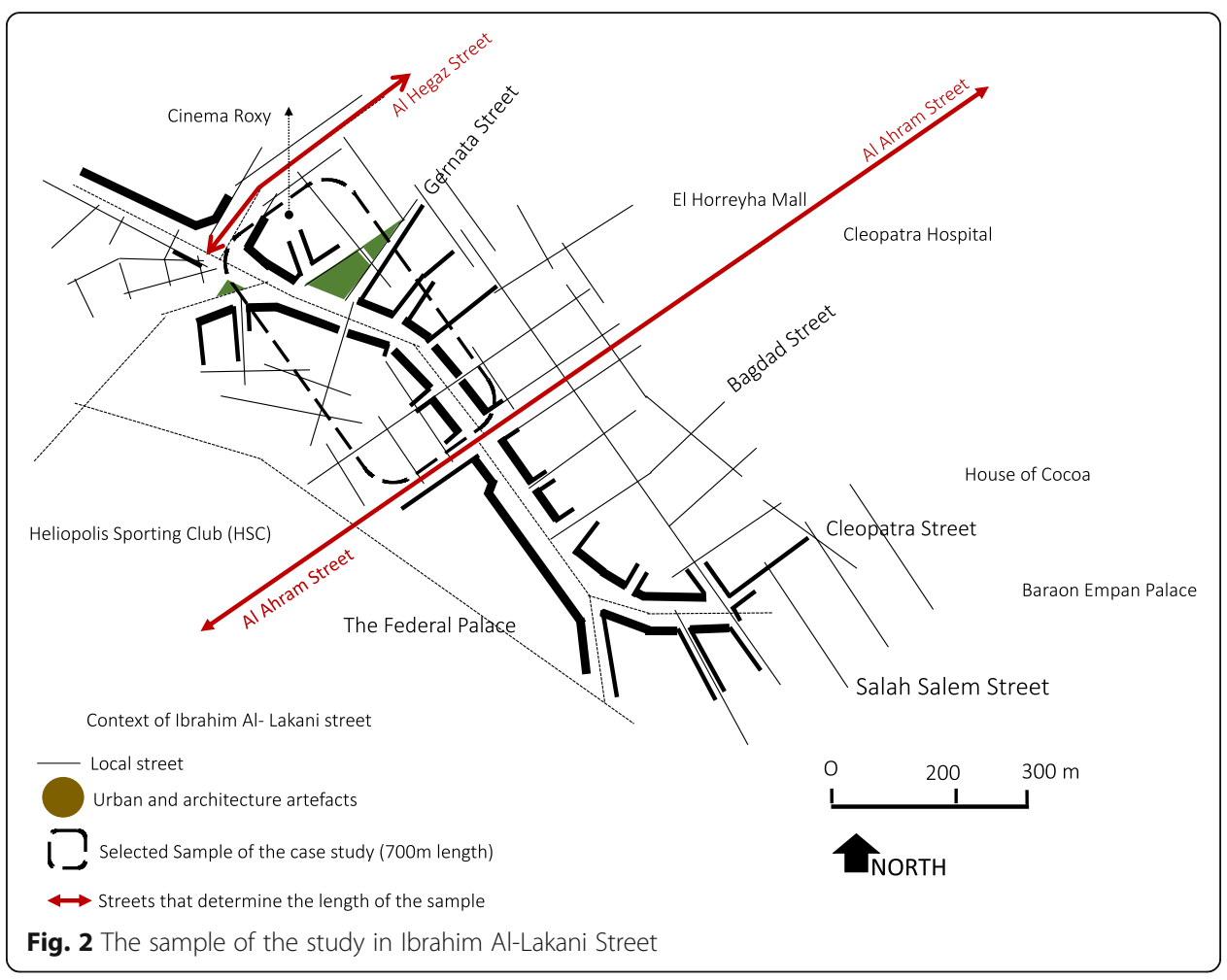




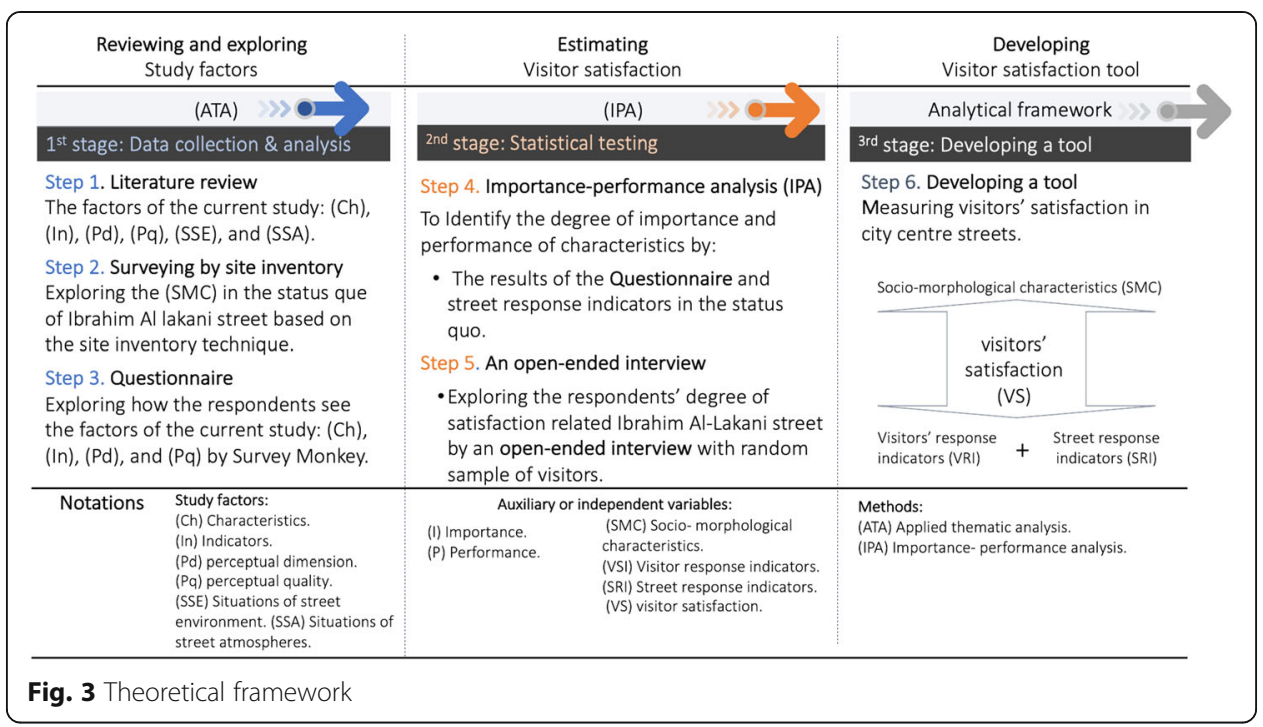

exploring variables by surveying the selected area through the site inventory (step 2) and an online questionnaire (step 3).

II. Estimating visitor satisfaction: The second stage investigated the importance and performance of study factors. The results find descriptive statistics to ascertain visitors' satisfaction with the selected site (step 4). Accordingly, explored visitor satisfaction based on this investigation using an open-ended interview for a random sample of street visitors (step 5).

III. Developing a tool: The proposed analytical framework provides a tool for visitor satisfaction developed to provide the designer with the possibility of a deeper understanding of existing street characteristics and perceptual quality, contributing to better street design in the future (step 6).

\section{Study design}

This study focuses on five concepts and employs two primary statistical techniques (see Fig. 3 and Appendix 2). Two dimensions of visitor satisfaction were measured by the situations, characteristics and indicators of the street environment situations, as shown in the theoretical framework in Fig. 3 in three issues. First, the socio-morphological characteristics of street environments were ascertained. Second, street response indicators and visitor response indicators pertinent to street situations were investigated. Third, developing a tool for measuring visitor satisfaction.

\section{Stage I: review and exploration: applied thematic analysis}

The first stage employed an applied thematic analysis (ATA) to classify the variables into three categories: (a) situations of street environments (SSE) and situations of street atmospheres (SSA); (b) socio-morphological characteristics (SMC); and (c) visitor response indicators (VRI) and street response indicators (SRI). The data collection process was dependent on a quantitative study that focused on reviewing and exploring the issues of the current study. The data mining relied on narrative analysis (NA) through Google, Academia and ResearchGate digital databases randomly using the list 
of variables mentioned above. This stage consisted of three steps that included a review of the factors in the literature and an examination of their presence in the status quo.

The first step summarised the findings of previous studies in two sections. The first diagram illustrated the interactions between eternal qualities $(\mathrm{Pq})$, perceptual dimensions (Pd) and SSE. The second diagram illustrated the relationships between typological characteristics and SMC, and VSI. This step summarised the physical and non-physical conditions of the urban environment and the physical and nonphysical factors that influence them (see Appendix 1 in supplementary materials).

The second step included surveying site inventory, utilising site-specific monitoring to investigate SMC in the specified site's three distinct parts. The survey included two sections. The first section was used to document the site inventory: its uses, activity locations, landmarks/symbols (architecture and artefacts), and the repetition events at loitering points in these three segments. The second section was used to ascertain the relationship between SMC and SSE in the three sections of Ibrahim Al-Lakani Street.

In the third step, a questionnaire was used to ascertain the extent to which respondents understood the consequences of SSA in the Egyptian context. This questionnaire aimed to ascertain the relative importance of SMC in perceptual quality criteria and principles. The sample size was estimated based on Eq. 1. The survey questions can be viewed from the link (https://www.research.net/r/Lakani). Subsequently, using data analysis from the site inventory, the researchers estimated the degree of performance for the selected site in the status quo (in step two).

$$
S=\frac{\frac{Z^{2}}{e^{2}} \times p(1-p)}{1+\left(\frac{Z^{2} \times p(1-p)}{e^{2} \times N}\right)}
$$

where $S$ = sample size, $N=$ population size, $e=$ margin of error (percentage in decimal form), $Z=\mathrm{z}$-score and $p=$ sample proportion [29].

To estimate the sample size at this stage, the anticipated population along Ibrahim Al-Lakani Street was 121,849 on 7 January, 2010 [16], and the sample size calculation indicated that 80 respondents should be included to ensure a confidence level of $95 \%$ and a margin of error of 11\% [35]. The researchers collected data for 2 years and 3 months, from 27 September 2018 to 31 December 2020. The respondents answered seven questions online and had the option of adding a comment. Based on a thorough understanding of the relationship between people and places, this survey examined the extent to which people are aware of the effects of urban atmospheres on their satisfaction with city streets. The second-stage survey addressed three issues and appeared in three stages. The initial step considered the relative significance of SMC. This step referred to the physical elements that contribute to forming an impression on visitors in four categories:

A. Architectural characteristics based on visual aspects: the attributes of the building facades [5]; 
B. Emotions reflected due to the aesthetics of reception and production: the availability of symbolic elements [19];

C. Daily sensual experience: Repetition of daily life experiences [4];

D. A contextual design: The emergence of technological impacts on the ability to recognise SSE. The third concern was regarding street problems that made people feel the loss of the sense of atmosphere of a place [3].

\section{Stage II: estimating visitor satisfaction}

This stage discovers importance-performance analysis (IPA). The fourth step found results by descriptive statistics to ascertain visitors' satisfaction with the selected site. This stage established the significance, performance and satisfaction of three variables: situations, characteristics and indicators, which are classified into five categories: SSE, SSA, SMC, SRI and VSI. Finally, using IPA, situations, characteristics and indicators were used as independent variables to quantify the degree of importance, performance and satisfaction for 42 study factors classified into these five categories.

In this issue, IPA was used to examine the performance of the three segments on Ibrahim Al-Lakani Street based on their relative importance for SSE, SSA, SMC, SRI and VSI. IPA was used to determine the importance that a visitor places on specific situations and characteristics and their actual level of performance. Visitor satisfaction was determined by using an online survey to assess the importance and performance of various characteristics. The significance of $\mathrm{Ch}, \mathrm{In}, \mathrm{Pd}$ and $\mathrm{Pq}$ and the degree of performance concerning Pq were calculated statistically by using this questionnaire. The dependent variable was visitor satisfaction, and the key independent variables included a list of paired dummy variables that indicated the performance of interaction factors such as SMC, SRI, VSI, as well as Pd and Pq. It determined visitor satisfaction based on the significance and performance of the characteristics via an online questionnaire. Statistical analysis was used to determine the significance, performance and satisfaction of items. The first category illustrated the characteristics of Ch that should be prioritised when attempting to improve street ambiences. The second category was concerned with SMC that contribute to visitor satisfaction. The third section examined how visitor satisfaction varies because of the interaction between the characteristics and indicators.

Descriptive analysis was used to determine the relative importance of Pd, Pq (criteria and principles), SMC and VSI, based on the results of the questionnaire employed in the third step.

The following proposed Eq. 2 was used to calculate the relative importance and performance of each characteristic:

$$
S C=\frac{n}{5 \times f}
$$

where $\mathrm{SC}=$ street characteristics in percentage, $n=$ number of each characteristics achieved (1-5) and $f=$ impact ration of actor importance.

In the fifth step, the results of the visitor satisfaction survey were obtained by using an 'open-ended interview administered to a carefully selected sample (Appendix 4 in supplementary material). The interview was conducted during a workshop through open meetings using Zoom Video Communications for the purpose of this study, 
ensuring the privacy and anonymity of the respondents. Before conducting the communication, an invitation letter was sent to the respondents. This letter contained a description of the meeting with researchers, a historical overview of Heliopolis neighbourhood and photographs of Ibrahim Al-Lakani Street's development, along with some snapshots of the current situation of the street. Thirty-six unknown participants accepted the invitation, which meant that each meeting included between eight and 10 participants. The workshop included meetings that lasted $8 \mathrm{~h}$ over 4 weeks. The meetings were held on weekends or on weeknights in June 2021. Each interview lasted approximately $2 \mathrm{~h}$ and was divided into two rounds.

The first round dealt with 20 items, while the second round dealt with 22 items. The open interview was conducted with the assistance of a visitor who was familiar with Ibrahim Al-Lakani Street. The researchers conducted the interviews in this study. Each meeting brought together individuals aged 22-60, including educated men and women. This study ensured that the participants included several specialists and students of architecture, design and urban planning, to identify conclusions that were accurate in terms of terminology and science.

Additionally, it was ensured that each meeting included a significant number of Heliopolis residents. At the outset of the meetings, the types of trips were identified: commercial, recreational and transitional trips, and residents in the area. The types of trip companions were also identified: individual, family or friends. Stay duration was identified as $1-2 \mathrm{~h}$, or more than $6 \mathrm{~h}$.

\section{Stage III: developing visitor satisfaction tool}

Based on the effect of street atmospheres in city streets, the sixth step proposed a procedure that may be applied to existing city streets and futuristic urban developments.

\section{Results}

\section{Applied thematic analysis (ATA)}

Step 1-Visitor satisfaction based on previous studies: The most significant findings of previous studies indicated that SMC are significant in determining street performance. As an independent variable, SSE has made seminal contributions to changing cities' characteristics. Recent research indicated that SSA significantly influences how people react to city sights and daily life experiences. Most early and contemporary research focused on visitor satisfaction, as illustrated in Fig. 4, which defines the relationships between these four groups of effects.

Step 2-surveying by site inventory: The researchers divided the study area into three segments, according to the site inventory notes. Figure 5 depicts the site inventory map, while Fig. 6 depicts eight scenes from the three segments of the study area. In terms of historical structures, the arcades' ground floor activities include retail stores, restaurants, cafes, airline offices, flower shops, juice bars, fast food restaurants, bookstores, newsstands and laboratories. The first and second floors include corporate offices, union halls, lawyers, engineers, and doctors' clinics.

Apart from a movie theatre, a gas station, car showrooms, hotels and several national and international banks, the street's various activities appear to be randomly distributed. Additionally, through direct observation, the goods extend beyond the shops on 


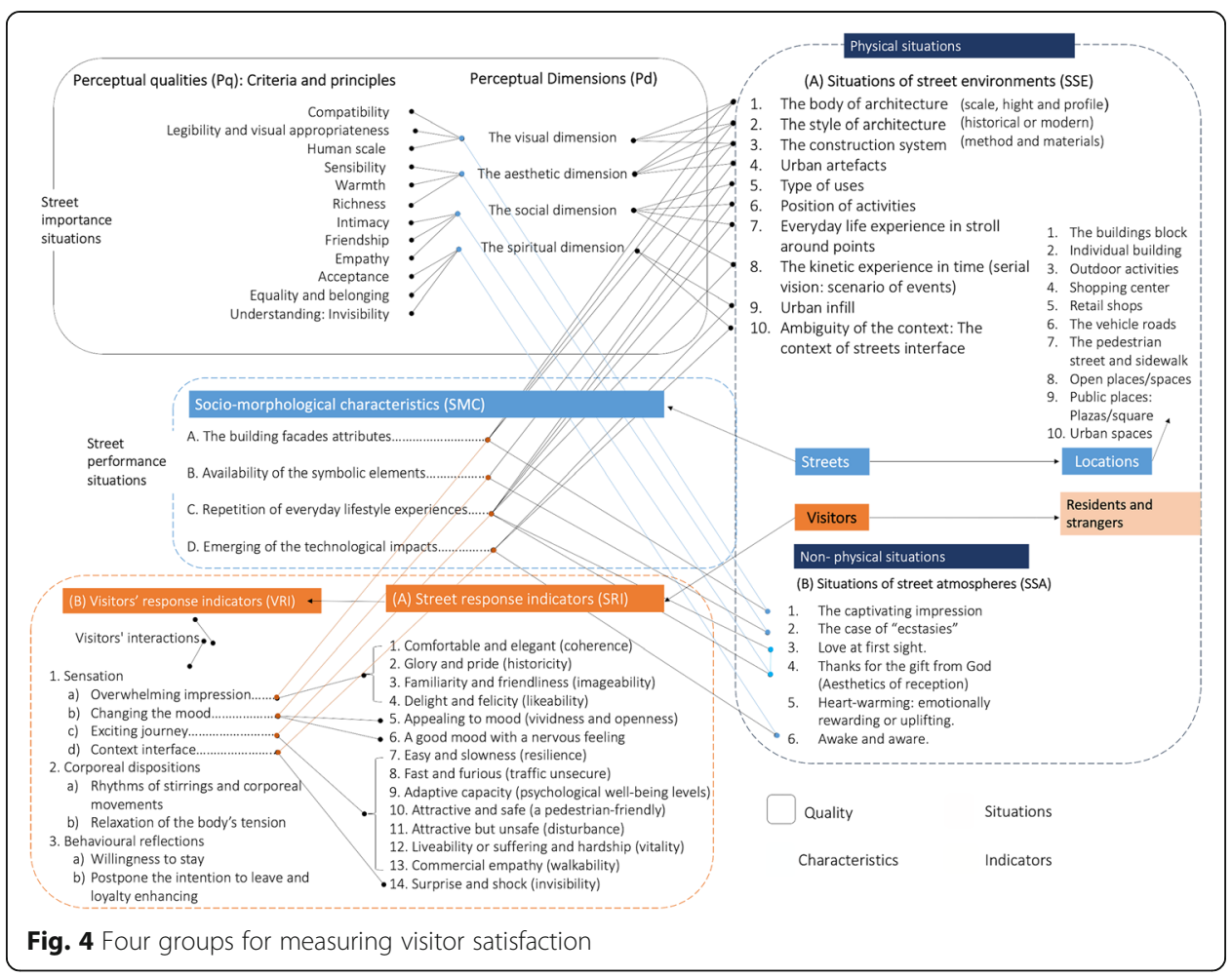

the sidewalks, where they mix with the wares of street vendors throughout the sample area. This street is devoid of parking: cars are parked in one or two lines along the sidewalks in the central lane in the vehicle road.

Step 3-the questionnaire: A survey found that changing levels of place satisfaction are likely to be related to changes in affective atmospheres. The results indicated that $11.25 \%$ of the respondents selected 'likely or unlikely' while $5 \%$ rejected the existence of this dependency entirely (Table 1 ).

Friendship and compatibility were ranked first and second, respectively, while belonging and comprehension were ranked last by the respondents. The remaining criteria were intimacy, empathy, sensibility and warmth (Fig. 7 and Appendix 5).

As illustrated in Fig. 8 and Appendix 5 of the supplementary material illustrates that haphazard development occurred in the middle segment of the street. In ranking the problems that make the users lose the sense of the importance of the urban atmosphere, a high number of the respondents felt that the visual image of the context altered their mood (28), while $10.26 \%$ did not share this feeling. The results also inducted that traffic congestion and garbage problems greatly impacted people's satisfaction with affective atmospheres in Ibrahim Al-Lakani Street (Fig. 9).

According to Table 2, the social (sensual) dimension was associated with $31 \%$ of visitors experiences, followed by the visual and spiritual dimensions at $29 \%$. The aesthetic (emotional) dimension, related to the aesthetics of reception and production, accounted for only $11 \%$ of the total. The results also figured out degree of performance with high number for availability of the symbolic elements 4 out of 5 on the scale of performance (Table 3). 


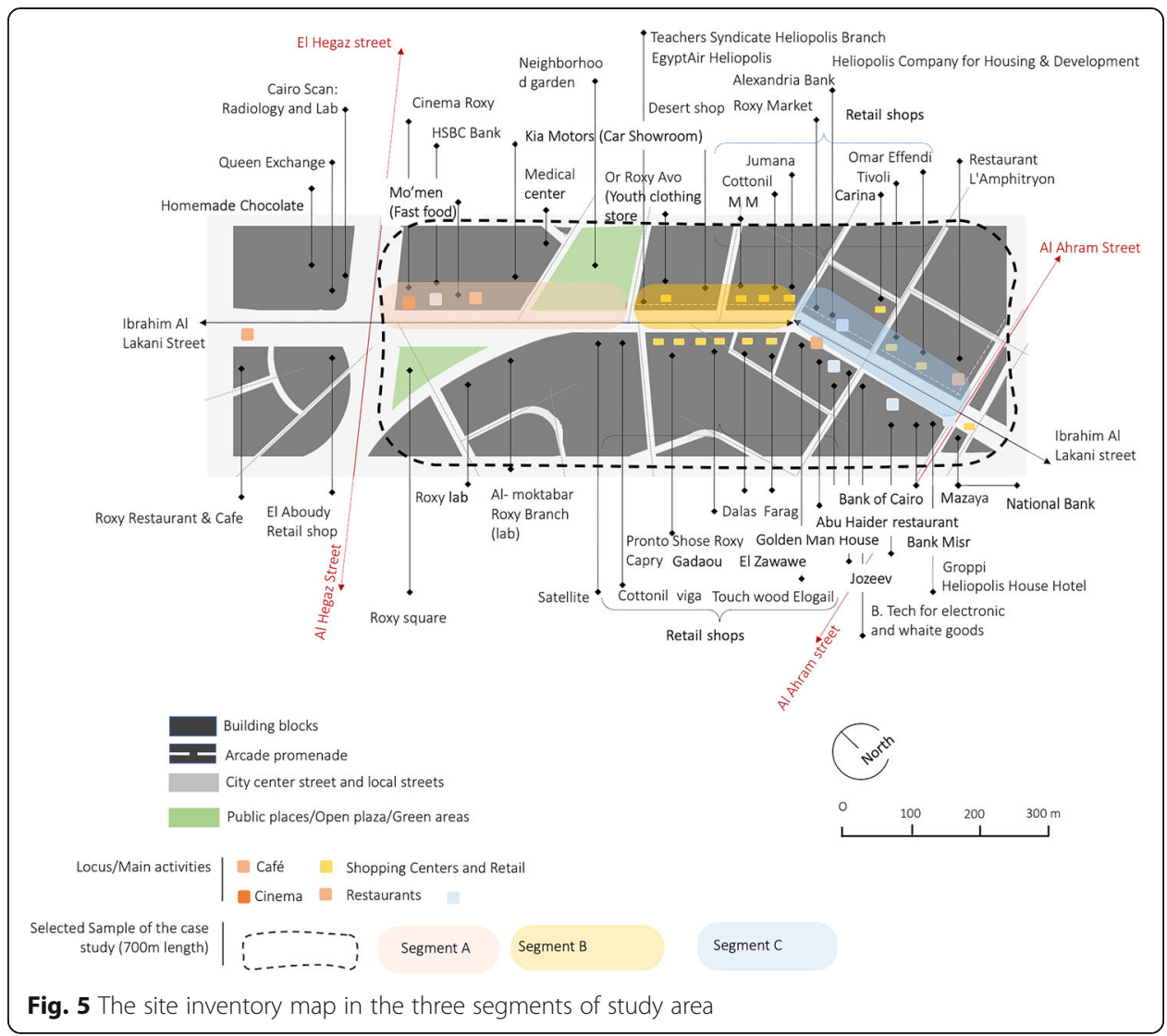

\section{Visitor satisfaction in the city street}

Step 4-Estimating the statistical testing by using IPA: The first stage was based on the results of the site inventory, the first step and the results of the questionnaire in the second step. Moreover, Fig. 10 shows the contradiction between the degree of importance between SMC and SRI. This was done to investigate consistency and coherence in the respondents' choices of visitors' responses to affective atmosphere indicators.

Step 5-An open-ended interview: The findings demonstrate that, despite the layperson's limited understanding of situations and atmospheres, the level of interaction with the open-ended interview far exceeded expectations. However, specialists, including architects, urban designers, urban planners, fellow professionals, teaching assistants and university students, accounting for approximately $60 \%$ of those interviewed, lent this survey some scientific legitimacy. The remaining $40 \%$ of the respondents interacted with the topics presented because their degrees qualified them to do so. Several of them had advanced degrees in urban geography, literature, psychology and sociology. By repeating the interpretation of each group and its constituents, results were obtained that appeared to be practical and reliable during the stage of discussing the findings and formulating reasonable conclusions.

The current study confirmed previous findings regarding the impact of 'street environment parking' on Heliopolis's distinctive architectural mass (building size, scale, style and systems). The interviewees confirmed that the building block on Ibrahim AlLakani Street has developed to the point where it creates an atmosphere that is unique and unmatched outside the Heliopolis area. Additionally, many of the structures on this 


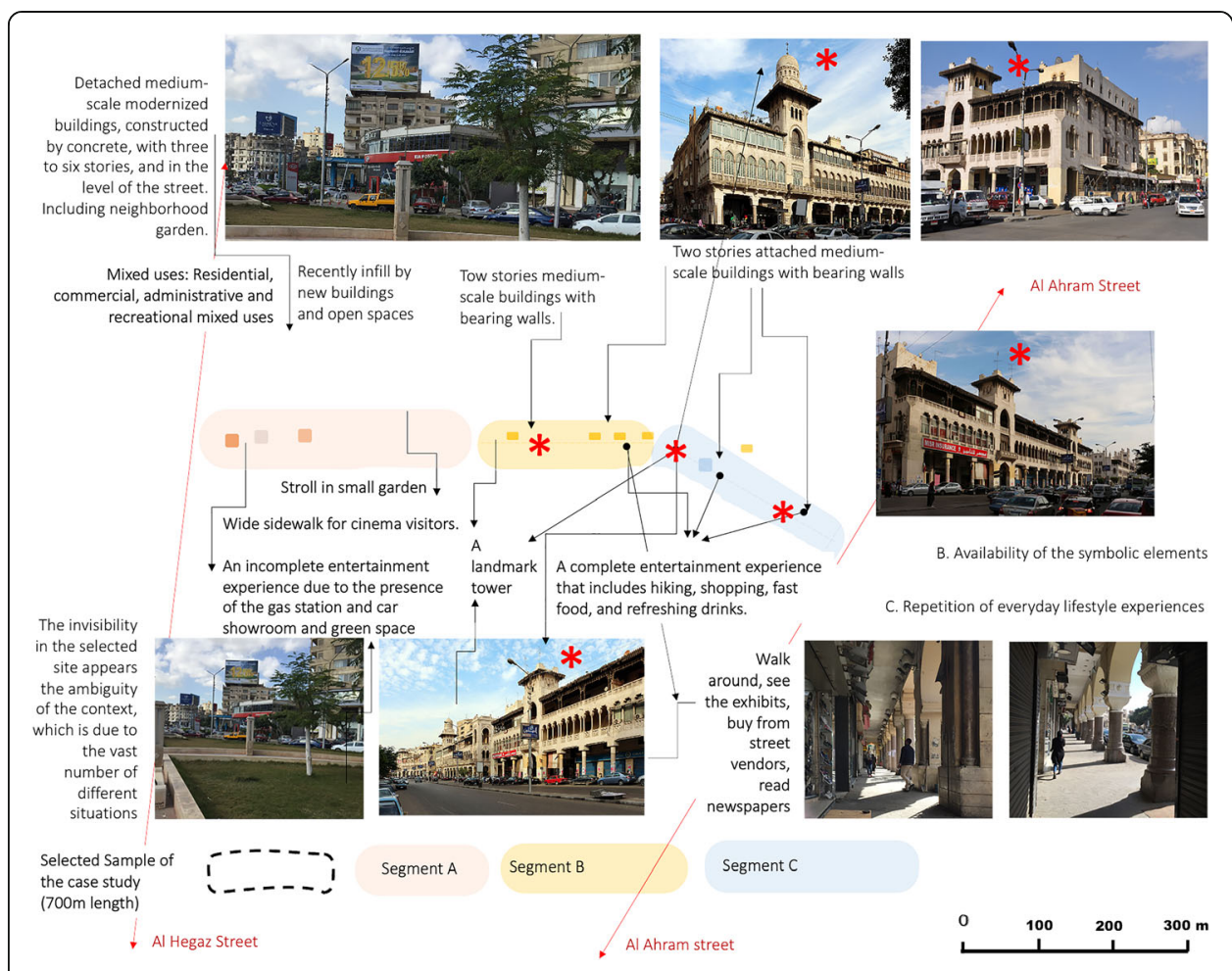

Fig. 6 The site inventory of eight scenes in the three segments of the study area

street were classified as urban artefacts, which become more apparent as one approaches Al-Ahram Street away from Roxy Square. An architect stated that dividing the street into three sections is a logical division: arcade buildings and the buildings adjacent to them on Al-Ahram Street on one side, and the buildings surrounding Roxy Cinema on the other side. He stated the following at the first meeting:

The visual effect of the first situation creates a visual and aesthetic atmosphere due to architectural design, whether due to architectural style or construction systems. In contrast, modern buildings built in the 1960s and beyond, I believe, lack atmosphere compared to arcade buildings, as we refer to them.

Table 1 The rank of the most important qualities for the respondents

\begin{tabular}{|c|c|c|c|c|c|c|c|c|c|c|}
\hline \multicolumn{2}{|c|}{ Perceptual qualities } & \multicolumn{4}{|c|}{ Choices } & \multirow{2}{*}{$\begin{array}{l}\text { Total } \\
71\end{array}$} & \multirow{2}{*}{$\begin{array}{l}\text { Score } \\
2.92\end{array}$} & \multirow{2}{*}{$\begin{array}{l}\text { Median } \\
2.00\end{array}$} & \multirow{2}{*}{$\begin{array}{l}\text { Main } \\
2.10\end{array}$} & \multirow{2}{*}{$\begin{array}{l}\text { SD } \\
1.18\end{array}$} \\
\hline Visual & Currency & $\begin{array}{l}\mathbf{1}^{\text {st }} \\
33\end{array}$ & $\frac{\mathbf{2}^{\text {nd }}}{13}$ & $\frac{3^{\text {rd }}}{11}$ & $\frac{4^{\text {th }}}{14}$ & & & & & \\
\hline & $\%$ & 46.48 & 18.31 & 15.49 & 19.72 & 100 & & & & \\
\hline Emotional & Currency & 10 & 22 & 28 & 10 & 70 & 2.46 & 3.00 & 2.54 & 0.90 \\
\hline & $\%$ & 14.29 & 31.43 & 40.00 & 14.28 & 100 & & & & \\
\hline Sensual & Currency & 14 & 17 & 20 & 24 & 70 & 2.16 & 3.00 & 2.73 & 1.16 \\
\hline & $\%$ & 12.86 & 24.29 & 28.56 & 34.29 & 100 & & & & \\
\hline Spiritual & Currency & 14 & 20 & 11 & 27 & 72 & 2.29 & 3.00 & 2.82 & 1.05 \\
\hline & $\%$ & 19.44 & 27.78 & 15.28 & 37.50 & 100 & & & & \\
\hline
\end{tabular}




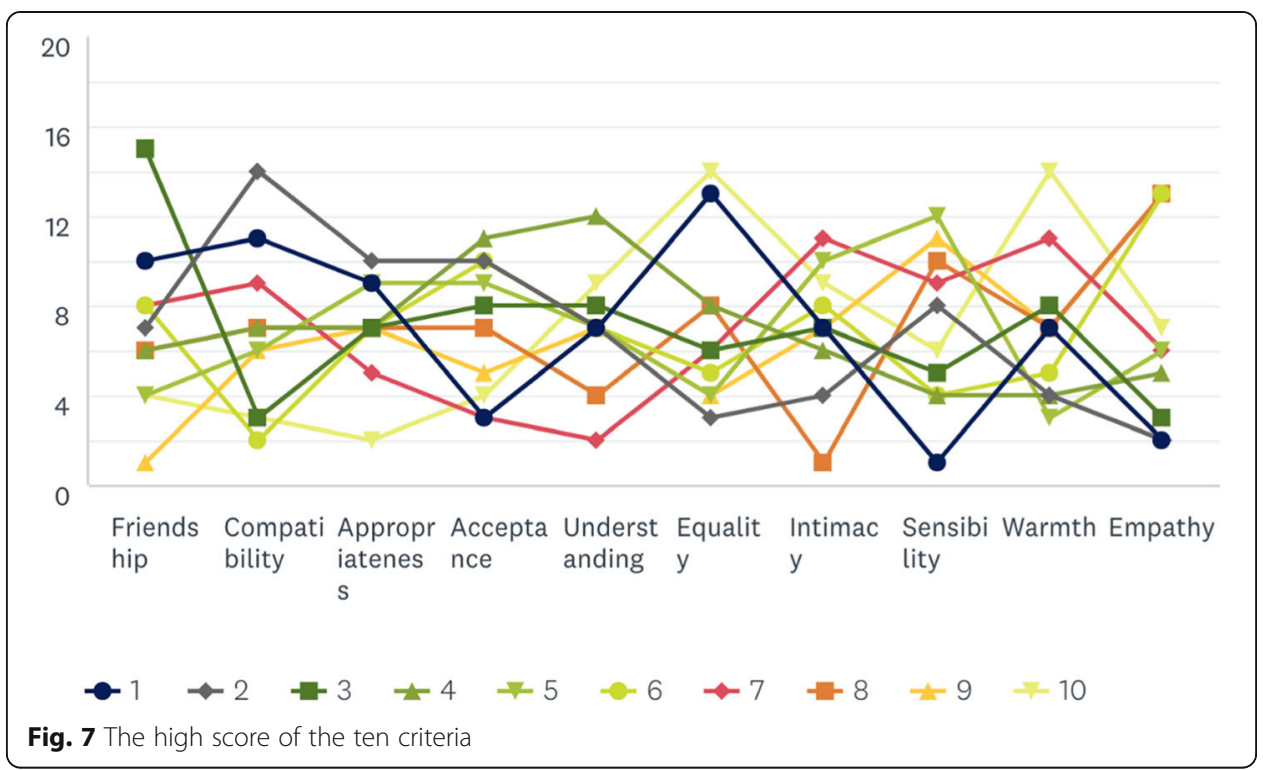

Numerous participants agreed that the atmospheres of the 1970s and the 1980s buildings lacked the atmosphere they were accustomed to in Heliopolis. They emphasised how life experiences have shifted dramatically in the modern era.

Although the building of Cinema Roxy and its surrounding context of modern residential buildings differed in shape, style, and design from the antique Belgian buildings, they once combined to create an aesthetically pleasing appearance. Today, the square is uninteresting, and lacks personality and atmosphere.

A woman stated that her true pleasure was strolling down this street, watching the shops and eating. A recent graduate from an urban design department stated the following:

Let me clarify something about the daily life experience derived from the current events. While the area is commercial and recreational, it is not like Al-Rehab or a gathering place [here referring to residential and recreational areas in Egypt's new suburbs, far from Cairo].

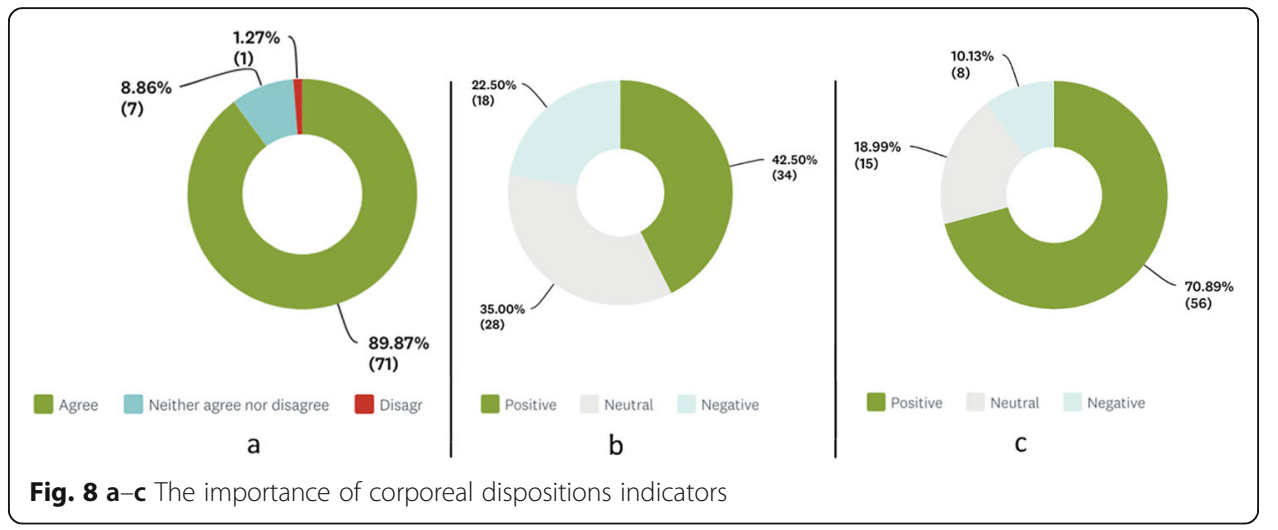




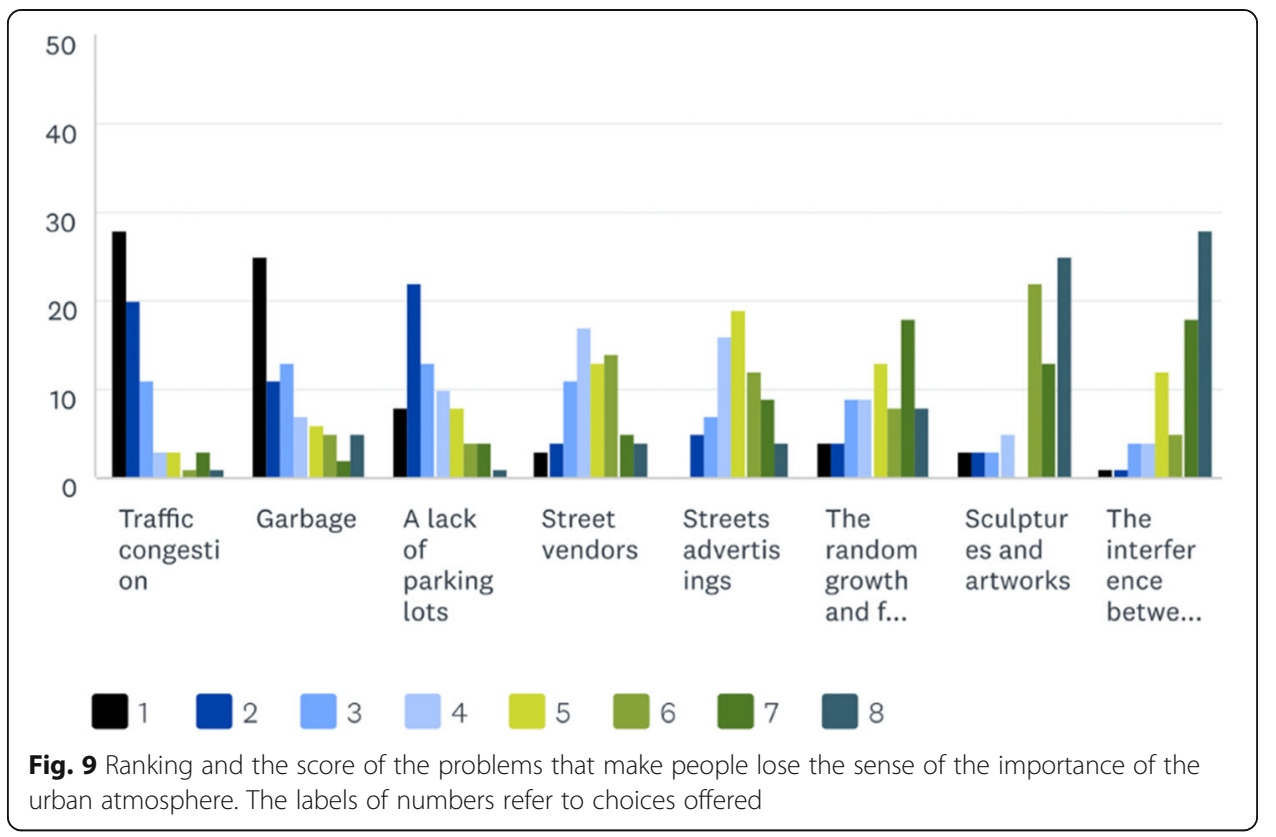

As a result of the discussion, it is determined that while the street provides a legitimate commercial and recreational experience, it is not entirely satisfactory because of several factors mentioned by the researchers' colleagues, including the following: spatial infringements by shop owners and street vendors, and lack of places to sit and enjoy the street experience. In relation to this, a young man mentioned his experience in the streets of ancient Rome and the outdoor restaurants on the sidewalks and how they established a wonderful atmosphere. The researchers defined the terms 'ambiguity of the context' and 'urban infill'; the findings indicated that it involves replacing an older structure with a new one and its suitability for the urban context. Both elements significantly altered the street's atmosphere, both visually and emotionally. The urban infill that took place at the beginning of the street in terms of Roxy Cinema and the use of building systems was utterly different from what characterised the urban character of

Table 2 The degree of importance (I) of Pd, SMC and VRI

\begin{tabular}{|c|c|c|c|c|c|c|c|}
\hline $\mathrm{Pd}$ & $1 \%$ & $\mathrm{Pq}$ & $1 \%$ & SMC & $1 \%$ & VRI & $1 \%$ \\
\hline \multirow[t]{2}{*}{ Visual } & \multirow[t]{2}{*}{45.8} & Compatibility & 16 & \multirow{2}{*}{$\begin{array}{l}\text { The buildings facades } \\
\text { attributes and urban } \\
\text { artefacts. }\end{array}$} & \multirow{2}{*}{29} & \multirow{2}{*}{$\begin{array}{l}\text { The captivating (overwhelming) } \\
\text { impression }\end{array}$} & \multirow[t]{2}{*}{89.87} \\
\hline & & $\begin{array}{l}\text { Legibility and } \\
\text { visual } \\
\text { appropriateness }\end{array}$ & 13 & & & & \\
\hline \multirow{2}{*}{$\begin{array}{l}\text { Aesthetic } \\
\text { (Emotional) }\end{array}$} & \multirow{2}{*}{14.1} & Sensibility & 1 & \multirow{2}{*}{$\begin{array}{l}\text { Availability of the } \\
\text { symbolic elements. }\end{array}$} & \multirow[t]{2}{*}{11} & \multirow{2}{*}{$\begin{array}{l}\text { The overwhelming impression } \\
\text { and the case of ecstasies: } \\
\text { changing the mood }\end{array}$} & \multirow[t]{2}{*}{70.89} \\
\hline & & Warmth & 10 & & & & \\
\hline \multirow{4}{*}{$\begin{array}{l}\text { Social } \\
\text { (Sensual) }\end{array}$} & \multirow[t]{4}{*}{14.1} & Intimacy & 10 & \multirow{4}{*}{$\begin{array}{l}\text { Repetition of everyday } \\
\text { lifestyle experiences. }\end{array}$} & \multirow{4}{*}{31} & \multirow{4}{*}{$\begin{array}{l}\text { Aesthetics of reception: Exciting } \\
\text { journey. }\end{array}$} & \multirow[t]{4}{*}{42.50} \\
\hline & & Friendship & 14 & & & & \\
\hline & & Empathy & 3 & & & & \\
\hline & & Acceptance & 4 & & & & \\
\hline \multirow[t]{2}{*}{ Spiritual } & \multirow[t]{2}{*}{19.2} & $\begin{array}{l}\text { Equality and } \\
\text { belonging }\end{array}$ & 18 & \multirow[t]{2}{*}{$\begin{array}{l}\text { Emerging of the } \\
\text { technological impacts }\end{array}$} & \multirow[t]{2}{*}{28} & \multirow[t]{2}{*}{$\begin{array}{l}\text { Awake and aware: The context } \\
\text { of streets interface. }\end{array}$} & \multirow[t]{2}{*}{1.37} \\
\hline & & $\begin{array}{l}\text { Understanding: } \\
\text { Invisibility }\end{array}$ & 10 & & & & \\
\hline
\end{tabular}


Table 3 The degree of performance for each segment of the street examined by the researchers

\begin{tabular}{|c|c|c|c|c|c|c|c|c|}
\hline \multirow[t]{2}{*}{$\begin{array}{l}\text { Socio-morphological characteristics } \\
\text { (SMC) }\end{array}$} & \multicolumn{2}{|c|}{$\begin{array}{l}\text { Importance (I) from } \\
\text { the questionnaire }\end{array}$} & \multicolumn{3}{|c|}{$\begin{array}{l}\text { Importance (I) \% } \\
\text { of the segments }\end{array}$} & \multicolumn{3}{|c|}{$\begin{array}{l}\text { Performance }(P) \text { of } \\
\text { the segments }\end{array}$} \\
\hline & $\overline{A I^{a}}$ & $\%$ & $\mathrm{S1}$ & S2 & S3 & S1 & S2 & S3 \\
\hline The building facades attributes & 1 & 31 & 1 & 2 & 4 & 6.2 & 12.4 & 24.8 \\
\hline Availability of the symbolic elements & 4 & 11 & 1 & 2 & 5 & 2.2 & 4.4 & 27.5 \\
\hline Repetition of everyday lifestyle experiences & 2 & 29 & 2 & 2 & 4 & 11.6 & 11.6 & 23.2 \\
\hline Emerging of the technological impacts & 3 & 28 & 1 & 1 & 2 & 5.6 & 5.6 & 11.2 \\
\hline
\end{tabular}

Heliopolis. It appears to have been influenced by the context dating back a century or more, the changes of the 1960s and the 1970s, and current events. A male participant stated the following:

The cinema closed its doors...the establishment lacked authentic atmospheres...and the advertising banners did not accurately reflect the establishment's character...Roxy Square lacked a temporal kinetic experience (or a sequential vision).

The second group's findings revealed two things. First, when viewed from the side of Al-Ahram Street, the street still leaves a charming impression. Second, the visitors lost these impressions in the segment of Roxy Square; thus, the gift of reception aesthetics was lost, though remnants remain on Al-Ahram Street. This is expressed by the following comment:

'Although 'Amphitryon' is not the restaurant we remember from our youth, the arcade buildings continue to elicit an atmosphere of grandeur and contentment as we walk from the beginning to the middle of the street.'

Some urban planners and designers believed that the Ibrahim Al-Lakani streetscape reflects their desire for a return to the past; the humane building scale, skyline and ornamental texture; materials; and colours all contribute to the street's status as an urban artefact. Although these ornate elements wore down over time, they evoke pleasant emotions and a fascinating historical atmosphere. The third

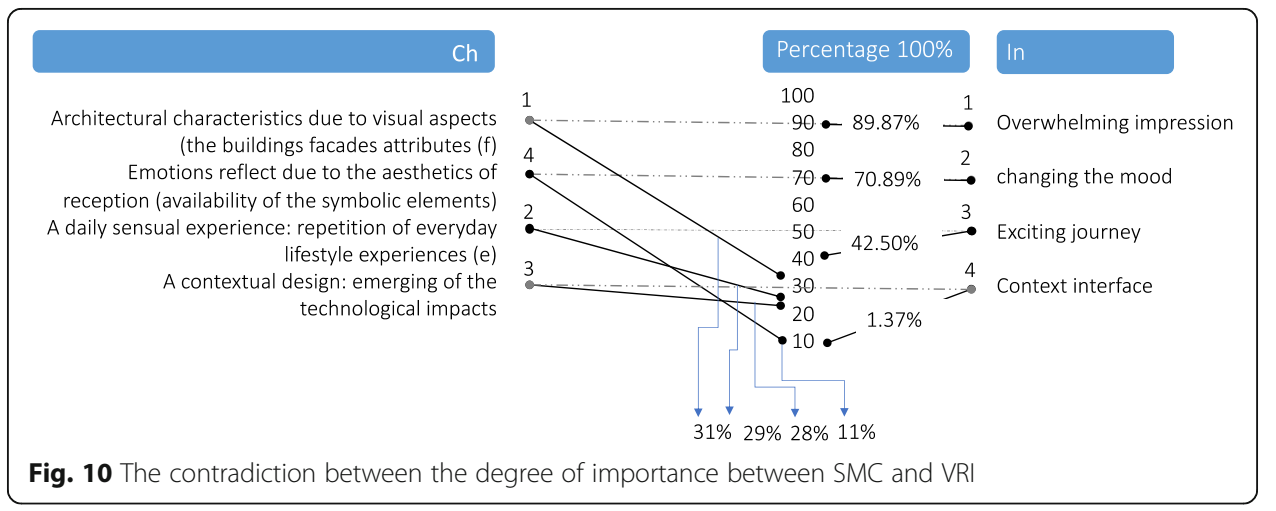


group's findings confirm that SMC have a significant impact on the atmosphere of a place and, thus, on satisfaction. Although many heritage buildings retain their original facades, two architects who attended the workshop expressed their objections as follows:

'The objection is on the painting of the facades...it hides the symbolic element of the place', and 'The street was an urban artefact... now it has lost its value due to painting the arcade buildings as well as changing characteristics'.

The findings confirmed that while the street life experience is a stereotypical recurring experience, it still leaves visitors satisfied. Furthermore, except for a few billboards, technology has largely unaffected the place. Regarding the billboards, a student of science and technology pointed out the following:

The billboards fill the place in a way that destroys the street's atmosphere...It has nothing to do with smart technology.

The fourth group took some time to gather impressions and indicators of street reactions. The 36 participants agreed that the street had lost its elegance and comfort. However, they stated that the arcade buildings continue to inspire glory and pride, especially as people descend the arcades, which also provides a mood change, particularly when coming from a road exposed to sunlight. This path is pedestrian-friendly and visually appealing when confronted with hardships encountered abroad. On the other hand, commercial empathy vanishes as a result of the mixing of activities without a clear orientation towards a particular type of journey and the unbalanced treatment of numerous activities. Roxy Square never fails to astound and surprise visitors; a single glance reveals the stark asymmetry between Roxy cinema, the gas station, apartment buildings, mixed-use buildings, central islands, sidewalks, lampposts and electronic, wooden or plastic billboards. One of the participants made the following observations about this scene:

Believe me, every time I drive from Al-Ahram Street to Roxy Square, I am shocked near the park that separates the arcade buildings from the square...Every time I feel as if I have moved from one location to another...I am dissatisfied with what is happening in this square.

Numerous participants concurred on their reactions to the street environment. While they appreciated the overwhelming impression created by Heliopolis' architecture, considering its current state, they stated that the preservation of the historic buildings appeared to be in the hands of non-experts. Some open restaurants may evoke memories through the smells emanating from them, but they quickly dissipate day or night due to occupancy, crowding, noise and lack of care to arrange and furnish the place.

A female participant made the following observations:

The experience has lost its lustre. At times I find it frustrating, and the only thing that motivates me to continue is necessity. 
Certain participants stated that that they can only stay for as long as it takes to finish their tasks. A female participant stated the following:

Nothing motivates me to stay...even standing up to eat is inconvenient due to overcrowding.

This, in principle, can give rise to the importance of users' reaction while preparing development plans for the site. This is only a limited study, and the full potential of the approach has not been proven. The overlooked of users' perspective about urban atmospheres can overlooked in some situations and thus requires a more detailed analysis.

\section{Discussion}

This study found that visual and aesthetic dimensions represent the most influential elements of perception and enhance visitor satisfaction. The opinion poll results showed that the facades of ancient buildings, urban artefacts and the symbolic elements are the most critical and formative places. A previous study by Biehl-Missal [7] and Elshater et al. [19] found that urban artefacts create a visual impact on visitors.

The previous studies regarding the multisensory effect of ornate elements agreed with the comments of the participants in the workshop and their satisfaction that increases each time they view the facades of ancient buildings [20]. Additionally, this issue is underscored by the overwhelming impression created by these structures $[6,9,13]$. Many participants aged over 40 confirmed this issue, and a majority of their comments was regarding the positive feelings invoked by the arcade buildings, regardless of the passage of time, and that these feelings were felt every time they went to Heliopolis. The visual dimension has a powerful impact on the satisfaction or dissatisfaction of street visitors $[8,30,40]$. It can change their mood, especially if they consider the behavioural interventions and changes in the images they were accustomed to in the past, which causes them to be spiritually affected by changing what they are accustomed and to build happy memories. This finding demonstrates that mood is an essential component of the visual perception of the environment [36] by assessing experience based on visual resource management across landscape architecture to create a high environmental visual quality. Additionally, the lack of commitment to applying the standards and principles of urban design that achieve quality in the streets of cities led to a decrease in satisfaction with Ibrahim Al-Lakani Street. Moreover, wide streets with tall buildings create sub-optimal street experiences. The respondents wrote in their comments that, although there have been many positive developments in Heliopolis, many historical buildings have effectively ended their influential role, as negative changes in heritage assets have reduced the appeal of this place.

It was found like previous research by Abusaada and Elshater [6] that the variables of urban form, especially in the uses and functions of the street, led to a sharp change in behaviour and played an essential role in understanding and accepting or not accepting the new experiences of daily life and the change brought about by the aristocratic atmosphere of the outdoor places. This, in turn, also affected the change of common social meanings regarding visitors' satisfaction with the place and the degree of their association with it, either negatively or positively. The respondents' suggestions focused on arranging residential, administrative, commercial and recreational activities in 
different sections of the street [38] since, currently, there is a random arrangement of buildings, especially regarding the locations of activities on the ground floor of ancient buildings and modern buildings that overlook the streets directly. This issue caused an apparent confusion in the visual and aesthetic effects, and consequently, caused a very negative transformation because of its inability to form a behavioural experience based on discrete events or even when forming a connected life experience $[22,25]$. Similar to previous research that results confirmed that the satisfaction brought about by the harmony between urban form and daily life experience [2]. Moreover, the results concluded that attracted people to the area and kept them there for more extended periods that has been affected by the changes in the street, as well as by changes in the nature of the users (social, economic and age groups). Thus, these changes have affected the length of visitors' stay and site selection. Another possible way to enhance the attractiveness of the streets for social activities is by rearranging the placements of activities to create an experience of sequential events $[6,22,25]$.

The results related to the visual impact situations (i.e. the urban architectural style and material compatibility) revealed that the three parts of the street have the most impact because they make the built environment evoke vivid feelings and help generate widely shared societal meanings among the community members. In this case, it is essential to emphasise that the respondents in this study confirmed that the visual dimension is still the first in terms of influence, followed by the social dimension (multiple sensory experiences), the sensory dimension (aesthetic experience) and the spiritual dimension. While the results of the open interviews showed people's interest in understanding the effect of the street's atmosphere on people's satisfaction with the place in the above-mentioned order, they indicated that the spiritual dimension-after they understood its meaning-is vital. Therefore, the suggestion here was to ask people to pay more attention to the idea of invisibility, which focuses on having a new building within the existing context. While placing billboards on heritage buildings, the relationship between the facade and the background should be considered [2, 31, 40].

Another possible avenue would be to respect the design of old streets. The visual and aesthetic dimensions are positive issues that prioritise the characteristics of the urban environment of the street and then achieve visitor satisfaction [11]. The high-quality visual environment helps visitors achieve emotional and mental well-being. Positive effects include reduced stress, decreased physiological arousal, increased fascination, decreased effort in forced concentration and a means of experiencing and strengthening the extended self. Adverse effects cause stress or negative feelings, which hinder the achievement of one's goals. The quality of the visual urban environment can be enhanced based creating entertaining experiences to maximise visitor satisfaction through walking and viewing.

\section{The proposed analytical framework}

The proposal presented the priorities of street characteristics to raise visitors' satisfaction in terms of the effects of affective atmospheres. This framework includes four phases, data collection, data analysis, statistical setting and development of the tool measuring visitors' satisfaction in city streets (Fig. 11). 
1. According to the finding of a limited literature review in introduction and surveying the selected area by site inventory, the first phase reviewed the factors of the study in literature and reality. These factors are the physical and non-physical situations of affective atmospheres, which lead to visitors' response of affective atmospheres indicators (In), the physical and non-physical situations of street environments, which lead to socio-morphological characteristics $(\mathrm{Ch})$, the dimensions of affective atmospheres (Pd) and the perceptual quality (criteria and principles) of affective atmospheres (Pq).

2. The second method is spatial analysis to provide the quality of the site related to examine the impact on the perceptual quality on socio-morphological characteristics for the three segments of status quo of the street. The third phase is the statistical testing to explore visitors' satisfaction, which includes three steps. The $1^{\text {st }}$ step is descriptive and importance-performance analysis based on the online questioner to identify the degree of importance of $(\mathrm{Ch})$ and $(\mathrm{In}) ; 2^{\text {nd }}$ step is explorative impact-range performance analysis in the three segments of the selected site in the status quo.

3. Third step impact asymmetry analysis (IAA) to identify visitors' satisfaction (VS) based on an interview. The third phase is spatial analysis to evaluate the relationships between the quality of the streets and visitors' satisfaction based on (Ch) and (In) by using space syntax analysis. Thus, a tool for visitors' satisfaction was developed to provide the designer with the possibility of a deeper understanding of existing street characteristics quality, contributing to better street design.

\section{Developing a tool}

As an analytical tool, this strategy depends on four intersecting groups: the situations of city streets (a set of circumstances), dimensions and perceptual qualities (satisfying people's expectations through design guides), assessment tools (an action and process of performance) and urban policies (a shared vision and goal). This tool provides a strategy to consider visitor satisfaction and revolves around four aspects of performance as follow:

1. Expecting: Selecting a place that helps provide suitable situations to create street atmospheres, considering the characteristics that reflect corporeal disposition indicators.

2. Executing: Applying the four dimensions that affect people's reactions, including 10 perceptual qualities, to explore visitor satisfaction.

3. Effectuating: Using guidelines based on the dimensions of urban design, and respecting visual, perceptual, temporal and technological aspects related to achieving place satisfaction.

4. Evaluating: Exploring place satisfaction by using conventional and digital methods.

\section{Conclusions}

This study, which focuses on the features and indicators of the street environment and street atmospheres, used ATA and IPA to assess visitor satisfaction in city streets. 


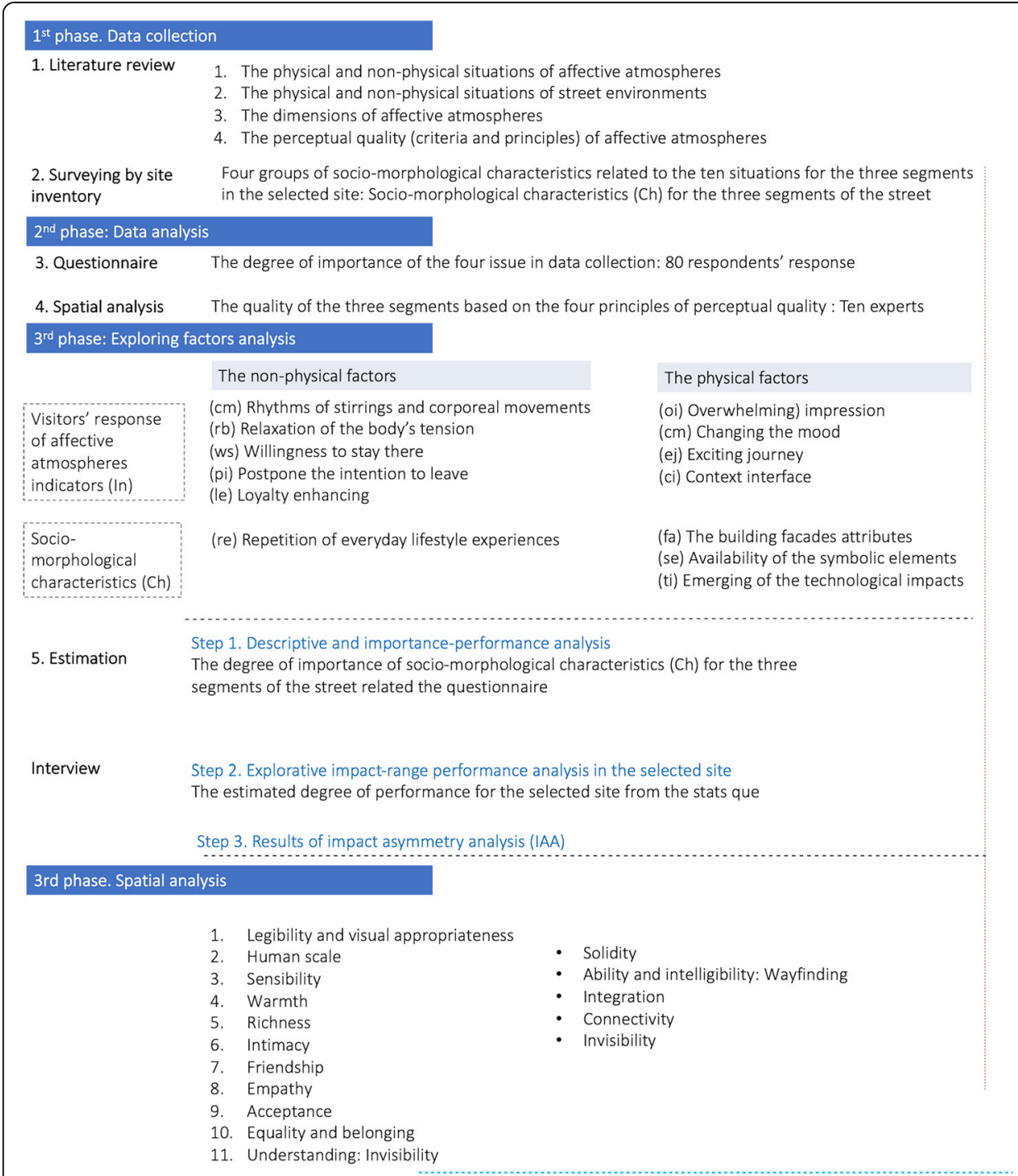

Fig. 11 Putting the method and materials into a context: a tool revive visitor satisfaction

Using a mixed-methods study strategy that included a literature review, site inventory, questionnaires and open-ended interviews helped develop a study focused on satisfaction with multiple characteristics and indicators. Forty-two variables worked together to create the atmosphere of Ibrahim Al-Lakani Street. The results validated the effectiveness of re-energizing concepts such as situations and atmospheres in the Ibrahim Al-Lakani Street in Cairo, Egypt, a street confronting a critical issue regarding community-environment relationships. Furthermore, as SMC have been studied, researchers can investigate how these factors affect people's behavioural responses to varying urban environments. Consecutively, the researchers used the main finding derived from previous studies to validate the SSE and SMC with actual visitor experience in Ibrahim Al-Lakani Street as one of the Egyptian streets, which already has substantial challenges regarding the relationship between people and places. The present research used ATA to review the typical patterns of visitor responses to affective atmospheres, such as characteristics (Ch) and indicators (In) across a dataset. 
Accordingly, the researchers were able to explore how SMC change people's responses according to changes in the street atmosphere through open-ended interviews with a random sample of visitors to determine their views.

This study offers insights into the physical and non-physical situations of the city street environments, which contributes to changing the situations and characteristics of the places and their perceptual qualities. These changes in situations, characteristics, and qualities help build a framework that includes four dimensions and 10 perceptual qualities. This framework explores the affective atmospheres in city streets based on place satisfaction. The results revealed that the visitors expressed low satisfaction regarding socio-morphological transformations based on the perceptual dimensions and qualities, implying that the service quality attributes in these two dimensions should be maintained. The interviewers showed a moderately high level of influence due to the impact of SSE and a low level of influence that occurs due to the impact of SSA.

In addition, SMC effects on the visitor satisfaction concerning the perceptual dimensions. For instance, to improve visitor responses, there is a need to carefully study two issues: (a) corporeal dispositions (rhythms of stirrings and corporeal movements), and relaxation of the body's tension. (b) Behavioural reflections (willingness to stay and postpone the intention to leave) and loyalty enhancing. In another context, street response indicators need to improve the attributes of building façades, the availability of symbolic elements, repetition of everyday lifestyle experiences and carefully consider emerging technological impacts. Future research should consider the potential effects of the relationships between situations and perceptual qualities more carefully, such as changing daily or lived experiences and the aesthetics of reception. These are the key components in future attempts to overcome and prevent indicators emanating from the absence of appealing characteristics of city streets. In future practical research, it is crucial and would be appropriate to test the proposed analytical framework at different urban scales, especially in the comparison between the historic city and new neighbourhoods.

\section{Abbreviations}

The first study factors

Ch: Characteristics; In: Indicators; Pd: Perceptual dimension; Pq: Perceptual quality; SSE: Situations of street

environment; SSA: Situations of street atmospheres

Second independent variables

SMC: Social morphological characteristics; VSI: Visitor response indicators; SRI: Street response indicators; VS: Visitor satisfaction; I: Importance; P: Performance

Third methods

ATA: Applied thematic analysis; IPA: Importance-performance analysis; IAA: Impact asymmetry analysis

\section{Supplementary Information}

The online version contains supplementary material available at https://doi.org/10.1186/s44147-021-00022-y.

Additional file 1. 


\section{Authors' contributions}

The authors, $\mathrm{HA}$ and $\mathrm{AE}$, of the present work declared that their role in conducting this research was distributed equally; they both conceived and designed the analysis and contributed to the data discussion. All authors of the present work have read and approved the manuscript. They also declared that the work presented here is solely on their own.

\section{Funding}

The authors of the present work confirmed that there no funding was received from any resource.

\section{Availability of data and materials}

The authors confirm that the data supporting the findings of this study are available within the article and its supplementary materials. All data generated or analysed during this study are included in this published article and its supplementary information files. The datasets generated and/or analysed during the current study are available in the Figshare repository [https://doi.org/10.6084/m9.figshare.15000405.v1].

\section{Declarations}

\section{Ethics approval and consent to participate}

The current work applies compliance with ethical standards in the following: Research involving human participants and or animals

There are no animals involved. Regarding human participants, the researchers of the current work used a video call with unknown six experts on the internet. The authors do believe that there is do not need for an agreement (or informed consent) from the experts.

Informed consent

There is no information/issue to be collected.

Data collection and analysis

The authors confirm that the results presented in this study were mainly prepared for this research during 2018 and 2020. There is no similarity in research design, or results could be found between any previous research conducted by the authors of the present work or anybody else.

\section{Competing interests}

Both authors are associate editors for the Journal of Engineering and Applied Science. They confirmed that there is no conflict of interest to be declared.

\section{Author details}

${ }^{1}$ Architecture Department, Housing and Building National Research Center (HBRC), Cairo, Egypt. ${ }^{2}$ Department of Urban Design and Planning, Ain Shams University, Cairo, Egypt.

Received: 9 July 2021 Accepted: 27 August 2021

Published online: 29 October 2021

\section{References}

1. Abusaada $\mathrm{H}$ (2020) Strengthening the affectivity of atmospheres in urban environments: the toolkit of multi-sensory experience. Archnet-IJAR 14(3):379-392. https://doi.org/10.1108/ARCH-03-2020-0039

2. Abusaada $H$, Elshater $A$ (2020) Urban design assessment tools: a model for exploring atmospheres and situations. Proceedings of the Ins Civil Eng - Urban Des Plann 173(6):238-255. https://doi.org/10.1680/jurdp.20.00025

3. Abusaada H, Elshater A (2021a) Competitiveness, distinctiveness and singularity in urban design: a systematic review and framework for smart cities. Sustain Cities Soc Vol 68:1-12. https://doi.org/10.1016/j.scs.2021.102782

4. Abusaada H, Elshater A (2021b) Revealing distinguishing factors between space and place in urban design literature. J Urban Des 26(3):319-340. https://doi.org/10.1080/13574809.2020.1832887

5. Abusaada H, Elshater A, Abd Elrahman A (2021) Articulating assemblage theory for salient urban atmospheres in children's environments. Ain Shams Eng J 12(2):2331-2343. https://doi.org/10.1016/j.asej.2020.09.021

6. Abusaada H, Elshater A (2021) Effect of people on placemaking and affective atmospheres in city streets. Ain Shams Eng J:1-15. https://doi.org/10.1016/j.asej.2021.04.019

7. Biehl-Missal B (2013) The atmosphere of the image: an aesthetic concept for visual analysis. Consum Mark Cult 16(4): 356-367. https://doi.org/10.1080/10253866.2012.668369

8. Blumentrath C, Tveit MS (2014) Visual characteristics of roads: a literature review of people's perception and Norwegian design practice. Transport Res Part A: Policy Pract 59:58-71. https://doi.org/10.1016/.t.tra.2013.10.024

9. Böhme G (2017) Atmospheric architectures: the aesthetics of felt spaces. (T. Engels-Schwarzpaul, Ed., \& T. EngelsSchwarzpaul, Trans.). Bloomsbury Academic, London and New York

10. Cao J, Cao X (2017) Comparing importance-performance analysis and three-factor theory in assessing rider satisfaction with transit. J Transp Land Use 10(1):837-854. https://doi.org/10.5198/jtlu.2017.907

11. Caoa J, Haob Z, Yangb J, Yinc J, Huangc X (2020) Prioritizing neighborhood attributes to enhance neighborhood satisfaction: An impact asymmetry analysis. Cities 105:102854. https://doi.org/10.1016/j.cities.2020.102854

12. Cheng L, Chu S, Zong W, Li S, Wu J, Li M (2017) Use of tencent street view imagery for visual perception of streets. ISPR $S$ Int J Geo Inf 6(9):1-20. https://doi.org/10.3390/ijgi6090265

13. Dewey J (2008) In: Boydston A (ed) The later works of John Dewey, 1925-1953: 1934, Art as experience, vol 10. Southern Illinois University Press, Carbondale

14. Dobrowolska A, Dobrowolski J (2006) Heliopolis, rebirth of the city of the sun. The American University in Cairo Press, Cairo 
15. Donga W, Cao X, Wu X, Dong Y (2019) Examining pedestrian satisfaction in gated and open communities: an integration of gradient boosting decision trees and impact-asymmetry analysis. Landscape Urban Plann 185:246-257. https://doi.org/10.1016/j.landurbplan.2019.02.012

16. Eldaidamony M, Shetawy A, Serag Y, Elshater A (2019a) Adapting geographies of gentrification in Egypt: lesson learned from Fatimid Cairo and Heliopolis. In: Hawkes D, Bougdah H, Rosso F, Cavalagli N, Ghoneem MY, Alalouch C, Mohareb N (eds) Heritage, Conservation of Architectural Heritage. Springer, Cham, pp 49-63. https://doi.org/10.1007/978-3-030-1 0871-7_5

17. Eldaidamony M, Shetawy A, Serag Y, Elshater A (2019b) Applying the gentrification indicators in Heliopolis district. In: Hawkes D, Bougdah H, Rosso F, Cavalagli N, Ghoneem MY, Alalouch C, Mohareb N (eds) Conservation of Architectural Heritage, Cham: SpringerLink, pp 65-76

18. Elshater A (2018) The Power of Photography in Urban Design Discipline: A Module Catalogue. International Journal of Architectural Research: ArchNet-IJAR 12(2):182. https://doi.org/10.26687/archnet-ijar.v12i2.1594

19. Elshater A, Abusaada H, Afifi S (2019) What makes livable cities of today alike? Revisiting the criterion of singularity through two case studies. Cities 92:273-291. https://doi.org/10.1016/j.cities.2019.04.008

20. Ghomeishi M (2021) Aesthetic preferences of laypersons and its relationship with the conceptual properties on building façade design. J Asian Arch Build Eng 20(1):12-28. https://doi.org/10.1080/13467581.2020.1782209

21. Guest G, MacQueen K, Namey E (2012) Applied thematic analysis. SAGE Publication, New York. https://doi.org/10.4135/ 9781483384436

22. Heng Y, Zhang F (2021) The complete path effect model of the three-dimensional street environment on street usage time. J Urban Des 26(4):514-529. https://doi.org/10.1080/13574809.2020.1863775

23. Insch A, Florek M (2008) A great place to live, work and play: conceptualising place satisfaction in the case of a city's residents. J Place Manag Dev 1(2):138-149. https://doi.org/10.1108/17538330810889970

24. Jacks B (2018) Photographs and spiritual atmospheres. J Interior Des 44(1):45-63. https://doi.org/10.1111/joid.12136

25. Lee H-S (2015) Measurement of visitors' satisfaction with public zoos in Korea using importance-performance analysis. Tour Manag 47:251-260. https://doi.org/10.1016/j.tourman.2014.10.006

26. Liebst LS, Griffiths S (2020) Space syntax theory and Durkheim's social morphology: a reassessment. Distinktion: J SocTheory 21(2):214-234. https://doi.org/10.1080/1600910X.2019.1641121

27. Lindley SE, Monk AF (2013) Measuring social behaviour as an indicator of experience. Behav Inf Technol 32(10):968-985. https://doi.org/10.1080/0144929X.2011.582148

28. Martilla JA, James JC (1977) Importance-performance analysis. J Mark 41(1):77-79. https://doi.org/10.1177/0022242 97704100112

29. Megahed G, Elshater A, Afifi SM (2020) Competencies urban planning students need to succeed in professional practices: Lessons learned from Egypt. Archnet-IJAR 14(2):267-287. https://doi.org/10.1108/ARCH-02-2019-0027

30. Nia HA, Atun RA (2016) Aesthetic design thinking model for urban environments: a survey based on a review of the literature. URBAN DESIGN Int 21(3):195-212. https://doi.org/10.1057/udi.2015.25

31. Offenhuber D (2008) The invisible display—design strategies for ambient Mmedia in the urban context. In: Proc. of 2nd Workshop on Ambient Information Systems. Ubicomp, Seoul

32. Olowoporoku O, Daramola O, Odeyemi G, Olaniyi K (2020) Navigating the urban space: assessment of residents' experience and satisfaction with the legibility of Ibadan municipality, Nigeria. Environ Qual Manag 30(2):21-33. https:// doi.org/10.1002/tqem.21710

33. Park Y, Garcia M (2020) Pedestrian safety perception and urban street settings. Int J Sustain Transp 14(11):860-871. https://doi.org/10.1080/15568318.2019.1641577

34. Rezvanipour S, Hassan N, Ghaffarianhoseini A, Danaee M (2021) Why does the perception of street matter? A dimensional analysis of multisensory social and physical attributes shaping the perception of streets. Archit Sci Rev 64(4):359-373. https://doi.org/10.1080/00038628.2020.1867818

35. Sample size calculator. (2018, 1231$)$. Retrieved from www.surveymonkey.com: https://www.surveymonkey.com/mp/sa mple-size-calculator/

36. Schmitz H, Owen R, Slaby M (2011) Emotions outside the box-the new phenomenology of feeling and corporeality. Phenomenol Cognit Sci 10(2):241-259. https://doi.org/10.1007/s11097-011-9195-1

37. Shaykh-Baygloo R (2020) A multifaceted study of place attachment and its influences on civic involvement and place loyalty in Baharestan new town, Iran. Cities 96:102473. https://doi.org/10.1016/j.cities.2019.102473

38. Stefansdottir H (2017) The role of urban atmosphere for non-work activity locations. J Urban Des 23(3):319-335. https:// doi.org/10.1080/13574809.2017.1383150

39. Zhang Z, Kai Fang XW, Chen L, Zhang W, Furuya N (2021) Characteristics, correlations of traditional street space elements and tourist density following spontaneous renovation: a case study on Suzhou's Shantang Street. J Asian Arch Build Eng 20(1):29-43. https://doi.org/10.1080/13467581.2020.1781647

40. Zumthor P (2006) Atmospheres: architectural environments—surrounding objects. Birkhauser, Basel

\section{Publisher's Note}

Springer Nature remains neutral with regard to jurisdictional claims in published maps and institutional affiliations. 